\title{
The Analysis and the Measurement of Poverty: An Interval Based Composite Indicator Approach
}

\author{
Carlo Drago ${ }^{1}$
}

\author{
University "Niccolò Cusano", Rome \\ NCI University in London
}

\begin{abstract}
The analysis and measurement of poverty is a crucial issue in the field of social science. Poverty is a multidimensional notion that can be measured using composite indicators relevant to synthesizing statistical indicators. Subjective choices could, however, affect these indicators. We propose interval-based composite indicators to avoid the problem, enabling us in this context to obtain robust and reliable measures. Based on a relevant conceptual model of poverty we have identified, we will consider all the various factors identified. Then, considering a different random configuration of the various factors, we will compute a different composite indicator. We can obtain a different interval for each region based on the distinct factor choices on the different assumptions for constructing the composite indicator. So we will create an interval-based composite indicator based on the results obtained by the Monte-Carlo simulation of all the different assumptions. The different intervals can be compared, and various rankings for poverty can be obtained. For their parameters, such as center, minimum, maximum, and range, the poverty interval composite indicator can be considered and compared. The results demonstrate a relevant and consistent measurement of the indicator and the shadow sector's relevant impact on the final measures.
\end{abstract}

Keywords: poverty, composite indicators, interval data, symbolic data

JEL: I32, I3, C43, C02

\footnotetext{
${ }^{1}$ Carlo Drago, University of Rome "Niccolò Cusano", via Don Carlo Gnocchi 3, Roma (Italy) e-mail: carlo.drago@unicusano.it. NCI University in London, Northern \& Shell Tower, 4 Selsdon Way, Isle of Dogs, London E14 9GL, United Kingdom
} 


\section{Introduction: Measuring Poverty}

Poverty measurement and, in general, poverty is a fundamental theme in Social Science literature. Poverty is a relevant refutation of human rights because it determines the impossibility of covering relevant expenses. Simultaneously, the relationship with well-being is more complicated because of both concepts' multidimensional structures (D'Ambrosio 2018). The measurement and monitoring of poverty are nowadays fundamental. At a macro level, poverty and inequality can impact modern societies in the long run. In literature, poverty and well-being are usually associated, and they are fundamental concepts to understand. In particular, poverty gravely affects a person's well-being (household, child's, migrants). Structural poverty can lead to an erosion of the basements on which the societies are born. At the same time, poverty can impact people's lives and be a problem for the institutions (it is necessary to think about the effects of poverty on children).

Poverty can eradicate institutions, and institutions can hurt poverty by creating obstacles to access to income. In this sense exists a specific causal loop that can become deleterious (see Sindzingre 2007). The United 2030 Agenda and the Sustainable Development Goals (SDGs) have created structured monitoring systems adopted in different countries (Mauro Maggino and Biggeri 2018). In this sense, it necessary to investigate the phenomenon, its determinants, and the possibilities of policy intervention. Simultaneously, identifying poverty states is very relevant and needs adequate methodologies (Alkire Foster 2011). In literature, another relevant problem is identifying the areas in which the poor live and design adequate intervention policies.

It is essential to measure the phenomenon and consider approaches to evaluate poverty size and then localize poverty situations using spatial data to design interventions. It is necessary to understand, in this sense, which the poor are and their geographical location. One of the most relevant aims is to design and evaluate adequate anti-poverty policies.

At this point, the adoption of adequate quantitative methodologies is necessary. These methodologies can detect and monitor poverty over space and space. Modern data richness calls for approaches that consider the synthesis of a group of indicators for the selected statistical units. Nowadays, in data richness, we can consider the situation we have in many different data cases. We can manage these data in order to measure the construct adequately. In this context, there are many different problems. The synthesis of indicators comprehends different phases (Maggino 2009 and also Nardo et al. 2005).

One relevant problem is to manage the different numbers of indicators (Mauro Maggino and Biggeri 2018). In this sense, we need an approach to synthesize the different indicators. In this sense, income is considered the most relevant predictor of economic status and well-being (Hansen Kneale 2013). At the same time, income is not a unique indicator to measure poverty. Exist at the same time other relevant indicators which can be considered in order to measure poverty correctly. So, in this case, it is necessary to consider different characteristics that can adequately consider other relevant aspects that can be useful to measure poverty. In this sense, there is also the use of many different approaches to measuring poverty using different 
methodologies. One relevant problem usually is that the different approaches can lead to different results, so it is usually necessary to provide sensitivity analysis and robustness checks of different approaches. These approaches are addressed to try to eliminate the subjectivity on several analyses. In this sense, the approach we will propose in this work wants to face this problem directly. In this sense, the proposal measures the indicator directly using interval data by simultaneously taking into account all the possible measurements obtained by the composite indicators. We have varied the different factors.

So, in the end, we obtain not a unique measure but an interval, and we can compare no single values but the entire intervals. Of course, we will interpret the different intervals adequately. In the first paragraph, we start by considering the different ways to measure poverty; in the second section, we will discuss the different ways to approach one of the most frequent ways to measure poverty, which is the composite indicators. In the third section, we will depart from the concept of composite indicators to describe the interval-based composite indicator's approach. In the fourth section, we will describe the data we have used, and in the last section, we describe the results we have obtained in terms of interval-based composite indicators of poverty in Italy. Multidimensional poverty calls naturally for the use of good indicators (Asselin 2002). Simultaneously, the problem to consider is that by considering different approaches and different methodologies. So it is necessary to take into account the different subjectivity of the choices, which can lead to different results.

This article is organized in this way: In the second section, we consider measuring multidimensional poverty using composite indicators. In the third section, we will examine and discuss the pros and cons of using composite indicators in measuring poverty; then, we present a new approach to the measurement of composite indicators by using interval data. Finally, we consider a real application by presenting the data, applying the methodology, and finally, the results.

\section{Measuring Multidimensional Poverty using Composite Indicators}

One relevant approach in measuring poverty is to use and consider groups of indicators to synthesize these indicators. Following Mauro, Biggeri, and Maggino (2018), this synthesis problem is very relevant to social indicators literature. The same authors consider a multivariate approach to measuring both multidimensional poverty and the analysis of well-being. At the same time, they consider the different indicators' synthesis to monitor the different outcomes obtained. In this sense, the authors' main contribution is that the general level of well-being that can be reached by the different persons can be linked with the level of substitutability of the different dimensions that can be obtained (Mauro Biggeri and Maggino 2018).

It is widely accepted today that poverty, for its nature, is a multidimensional concept (Anand Sen 1997 and also Sen 1981, 1985 and 1992). See about the multidimensional measurement of poverty Asselin (2002). The fundamental point is that poverty is a multidimensional concept. The multidimensional poverty is analyzed as 
a concept and the measurement methodologies by Alkire et al. 2015. If poverty is a multidimensional concept, it is necessary to analyze them by considering adequate methodologies.

So in this sense, relevant sets of indicators need to be considered. The choice of the different indicators, which explicitly characterize poverty as a concept, needs to consider the relevant dimensions like income needs and capabilities. It is essential, too, at the same time, to use other indicators related to the framework and the living situation (Lok-Dessalien 1999).

Another different approach is the approach followed by Abdu and Delamonica (2018), in which the authors consider a composite indicator to measure multidimensional child poverty. In this case, the multidimensional approach considers the complexity of the poverty phenomenon by considering different aspects that can be combined to provide a unique measure. This measure can be considered a synthesis. All these measures are relevant because they allow us to consider a measurement used to evaluate policies and programs explicitly.

Also, Kim (2016) raises the problem of considering a multidimensional and longitudinal perspective on measuring poverty. In this sense, it is the idea to measure the concept of poverty. The novelty introduced by the author is considering the dimension of time. At the same time, the author concludes that weighting of the "social capital" and the weight for the health can have a higher impact over time.

There are also some elements of uncertainty on collecting the right variables which can be considered. For instance, it is necessary to collect the income as a relevant variable on measuring poverty as a specific part of the surveys considered (Hansen Kneale 2013). One of the most relevant approaches to measure poverty is composite indicators. The composite indicators depart from the use of different indicators to provide a synthesis of the same indicators. We will consider the construction of the composite indicators in the following section.

At the same time, uncertainty and vagueness of the concepts could be significant. In this sense, poverty measurement needs to consider the fuzzy logic (see in this sense Cerioli and Zani 1990). This approach to measuring multidimensional poverty is also considered by Lemmi and Betti (2006), which use fuzzy sets. At the same time Costa and De Angelis (2008) and Mussard Noel (2005). These approaches show that exist many different dimensions to be carefully checked and considered on building composite indicators.

\section{Measuring Poverty by Composite Indicators: advantages and critical points}

Composite indicators are a relevant and consistent way to measure poverty. The usual approach is described in different works. The different indicators need to be synthesized, and it is necessary to consider different phases. (see in this sense Mauro Biggeri and Maggino 2018, Maggino 2009, Nardo et al. 2005). The different methodology selects the different indicators and then uses them to synthesize the underlying concept and 
measure the latent variable. Following Mauro Biggeri and Maggio 2018, the synthesis of different indicators allows monitoring specific outcomes of the considered statistical units.

Asselin (2002) reviews the different quantitative methodologies used to construct indicators on the multidimensional poverty context. The suggestion in Asselin (2002) is that author is that the use of the multivariate methodologies (principal component analysis), for example, can be an advantage for the choice of the specific weights used.

Different approaches in the measurement of the multidimensional poverty measurement are also in Kakwani Silber (2008). An alternative approach to analyzing the measurement of multidimensional poverty is by Bourguignon and Chakravarty (2003). Various approaches were proposed in this sense. De Muro Mazziotta and Pareto (2011) consider the composite indicator approach to measure poverty. Their approach is based on the penalty of the geographical areas characterized by single "unbalanced" statistical units. To approximate the different variables in composite indicators of poverty, we can usually follow the procedure, which leads to the construction of a composite indicator (Nardo et al. 2005). The different phases can be considered selecting the different indicators used, the aggregation method's choice, and the considered scaling of the different indicators used. In the end, we can obtain the considered latent variable as a component indicator. From the selection of the different indicators, we can scale the different indicators using various methodologies. Usually, we consider an aggregation function and a weighting scheme relevant to defining the single indicator's relevance or importance on the composite indicator created. Finally, it is possible to compare the different results obtained by the composite indicator constructed, and finally, it is possible to obtain a rank of the different values.

The relevant point is that the composite indicators' different components can hide relevant policy messages (see Nyiwul and Tarek 2006). In this sense exists many different critical points. Several choices, for example, the weighting of the composite indicator is based on subjective choices. Simultaneously, different choices can have a specific impact on the different results in terms of ranking. For this reason, robustness analysis and sensitivity analysis are usually followed by various analyses in which different approaches are considered and compared in order to evaluate the impact of each approach on the final results.

This analysis is usually performed by considering the different impacts on the rankings (Nardo et al. 2005). The approach we will consider is different. It is based on the interval data by taking into account simultaneously many different random measurements in which we try to cover all relevant options. In this case, sensitivity analysis could be fundamental to assess the different approaches and assumptions (Saisana Saltelli and Tarantola, 2005). The approach we will present in the next section allows us to "endogenize" the sensitivity analysis on the structure of the composite indicator computed. 


\section{Interval based Composite Indicators}

In this sense, composite indicators' construction can be based on subjective choices (Becker et al., 2007). These subjective choices (for instance, the composite indicator's weighting scheme) can lead to different results. The recent literature aims to construct the composite indicators, which can avoid the subjectivity of considering an assumption or a different one. So the target is to measure the different impacts of the suitable choices for the construction of the indicator (see in this sense Paruolo Saisana and Saltelli 2013).

Uncertainty techniques can be considered in this respect because they can measure uncertainty on constructing the composite indicator (for instance, using probabilistic rankings). See for a discussion Nardo 2005, Saisana Saltelli Tarantola 2005, and Greco et al. 2017. In this sense, the idea is to consider some robustness checks and sensitivity analysis by considering different assumptions to evaluate its robustness. This work aims to internalize this robustness by considering the interval of possible results, which can be obtained by varying the composite indicator's assumptions (see Drago 2017 and 2018 Gatto and Drago 2020). In this sense, it is essential to define the "model" for the composite indicators initially. It is essential to declare the different factors that lead to the composite indicator variability. From the model, we can identify the different internal sources of variability on the construction of the composite indicator, which leads to the uncertainty of the outcome.

At this point, we can consider several replications of the composite indicator considered by taking into account different combinations of the assumptions given. At every stage, we sample a different combination of assumptions, and we compute a different outcome. So we are explicitly considering an interval of all the possible obtained composite indicators by considering different combinations of assumptions on the composite indicator. The different results are collected, and they can be represented utilizing interval data (Billard Diday 2003, Billard 2008).

It is essential to note that our final result is interval data and not scalar data. In this logic, the interval allows to measure the uncertainty explicitly and permits to obtain a unique measure of the composite indicator (Sunaga 1958). The interval data own a specific algebra that allows different computations between intervals (Moore 1979 and Sunaga 1958) and statistical analyses (Gioia Lauro 2005 and Lauro Palumbo 2000).

So in this sense, we start to considering n number of different composite indicators with $n=1, \ldots N$ computed by random combinations of factors (Saltelli 2016 and Saltelli et al. 2008). Then we can build each interval based composite indicator by having:

$$
I[X]^{c}=\left[\underline{X^{c}}, \overline{X^{c}}\right]
$$

Where $\mathrm{c}$ is the considered, measured indicator for $c=1 \ldots C$

From the composite interval, indicator obtained we can compute the center 


$$
X_{\text {center }}^{c}=\frac{1}{2}\left(\underline{X^{c}}+\overline{X^{c}}\right)
$$

Furthermore, the range or the width obtained:

$$
X_{\text {range }}^{c}=\overline{X^{c}}-\underline{X^{c}}
$$

and finally the radius

$$
X_{\text {radius }}^{c}=\frac{1}{2}\left(\overline{X^{c}}-\underline{X^{c}}\right)
$$

The range and the width represent the variability for the considered interval composite indicators considered (Moore 1979). The parameters on which we can conduct the ranking analysis computed for the different intervals are the center, the minimum, the maximum, and the range (Mballo Diday 2005 and Song Liang Qian 2012). In order to measure the uncertainty, we can consider the difference between the upper and the lower bound of the computed interval (see also Grzegorzewski, 2018)

Finally, it is possible to compute at the same time a prototype (an average interval) using interval arithmetic. The interval arithmetic and the capacity to handle these composite indicators as intervals allow different advantages. First of all, they represent a more robust version of a classical composite indicator (based on a single value) and consider the internal variability. This one is determined by the various composite indicators' different performances on the same conceptual "model" (Nardo et al. 2005). Finally, they can be used and considered a scalar (it is possible to use, for instance, the center) and as an interval. In these two cases, it is possible to use analytical approaches as interval arithmetic in order to evaluate, for instance, a prototype (the statistical average of the different interval-based composite indicators). These indicators can contain a higher quantity of information so that the decision could be based on a more precise evaluation.

\section{Data and Methodology}

In the first step, we have to define the composite indicator model. The model is given by taking into account the following choices:

1) The relevant variables to be considered on the composite indicator

2) The relevant number on the total to be considered

3) The relevant aggregation function

4) The weights applied on the composite indicator

We consider the following variables for our composite interval indicator:

1. Families who live under a level of absolute poverty 
2. An index of economic difficulty

3. Social exclusion

4. Material deprivation

5. Low labor intensity

6. Income

All these data come from the ASVIS database, and we have considered it as a unique source. The date for each variable is 31/12/2016. The different indicators on their original name and their name are defined in table 1 . For each indicator, we consider as statistical units the Italian regions (for the year 2016). This dataset is chosen for the reliability of the data considered. In this sense, these six variables are the most relevant we can consider for our model. In this sense, we consider these variables the most relevant we can consider in the framework we are explicitly considering. So in this sense, we can proceed with the data analysis to evaluate our initial indicators and the structure of the indicators we will use as components or factors of our interval-based composite indicator.

Then we consider some descriptive analysis of our data. In this sense, we are considering and exploring our variables by observing if there are some situation which requests special attention (for instance the existence of relevant outliers). In this sense, we compute the descriptive statistics for our variables, and we examine the relevant structure of the data we can observe. Then we consider the correlation matrices of our variables. In particular, the correlation matrix can be usefully considered and visualized as a network with a specific threshold. These thresholds are relevant in practice because we can think of different specific weighting schemes not to weigh many variables that show a high correlation. In extreme cases, the approach can be made not to use these indicators.

So in this sense, to evaluate our choices, we consider some networks of the different variables to select eventual other variables when we face a higher correlation between some relevant variables. The network of variables is analyzed by considering several thresholds in order to show the data structure. We are ready to define at this point, our model of composite interval indicator by considering these specific factors (for the terminology in the composite indicators, see Nardo et al. 2005):

1. The indicator choice

2. The number of the indicator choice on the total number of indicator considered (in this sense, we can explore alternative configurations of the composite indicator)

3. The different weightings

At the same time, we normalize each indicator by providing standardization for each of them, and we aggregate the different indicators by obtaining the outcome. The algorithm is described in figure 1.

We also consider a choice of the relevant number of variables to be considered on the composite indicator. In the end, we use four different indicators on the total of indicators considered in order to evaluate also different measurement approaches in the construction of the poverty measure. In this sense, we can obtain different 
results due to the variability of the different measures (there can be a not strong association between the different indicators so that some regions can perform better in some indicators than in another one).

These characteristics can vary during the process of construction of the interval-based composite indicator. Other elements on the construction of the composite indicator do not vary. For instance, it does not vary the standardization of the different variables. At the same time, we do not consider any type of outlier detection and missing imputation (in fact, in our case, there are no missing data).

At this point, we define that we are also interested in computing the different interval composite indicators: a measure for the minimum, a measure for the maximum, and also two-measure, which can be differently interpreted as a center and a radius. It is possible to note that our composite indicator's outcome comprehends a ranking for the minimum, the maximum, the center, and the radius. The composite indicator can be interpreted as continuous. By the interval arithmetic, we can compute the different prototypes (the interval average, which can be useful as a benchmark).

At this point, a different composite indicator can be computed by considering a specific combination of composite indicators chosen by the four factors identified as relevant to the construction of an interval-based composite indicator. Each feature is sampled, and several 2,000 different composite indicators representing different results are obtained from the original data. Using these results, we can calculate the interval data representing the different poverty measurements by considering the defined model. To avoid outliers and provide a robust version of the interval, we consider the quantile 0.10 to be the minimum and the quantile 0.90 to be the maximum. The different rankings can be obtained by taking into account the different characteristics of the interval data: the minimum, the center, the maximum, and also the range. In the end, we can obtain a different ranking that can take into account the different scenarios.

The interpretation of the center (or mid-point) and the range (or width) is relevant. In this respect, it is possible to interpret the center as the "result" of the composite interval indicator, which is comparable to the most probable scenario (in this sense, compared to the classical composite indicator analysis, the center could be used). The interval range simultaneously is essential because it shows a relevant difference in the results between different composite indicators. It is also possible to observe some scenarios producing different relevant results when there are relevant differences between the different indicators used in constructing the composite indicator.

\section{Results}

In order to analyze the results obtained, we can firstly interpret the different interval composite indicators. The results are shown in Table 3 and Table 4. It is possible to observe that the center's rankings give similar results to the literature's current results. Concurrently, it can be noted that the results for the range give rise to essential 
considerations on the variability of the results. In particular, it can be observed that there is an apparent variation between the variables due, for example, to the shadow sector for the different first regions. It can be observed that Calabria, Sardinia, and Sicily are more diverse than in other regions.

By considering the table of the value for the center, the minimum, and the maximum, it is possible to observe that the Sicilia for the center's value shows the highest value, followed by the Campania and the Calabria. Then we can observe with a specific separation of values Calabria, Puglia, Sardegna, and Basilicata. The regions that perform better are Veneto, Emilia-Romagna, Toscana, Friuli Venezia Giulia, Lombardia, and Valle d'Aosta. If we consider the minimum scenario and compare the minimum for each region, the result does not change. It is also possible to observe the same ranking in the first position as for the interval center. The change on the highest value is related to the Basilicata, which performs with a higher value than Sardegna. The result for the minimum has the same result for the lowest values. So in this sense, the result is robust. Finally, let us consider the maximum value for the interval. We can observe that Calabria and Sardegna earn a position, so they perform in a slightly different way on the maximum ranking. By considering the maximum, Veneto loses a position than Emilia-Romagna, but overall, the situation is stable, considering the lowest performing regions in poverty.

The result is coherent, of course, with the observation of the range. The range of the interval is computed by considering the minimum and the maximum of the interval. Interestingly, Calabria, Sardegna, Sicilia, and Molise show the highest range between the minimum and the maximum computed. Toscana, Lombardia, Liguria, and Emilia-Romagna show the lowest results computed. A possible interpretation is that the different results depend on the shadow sector; some variables can perform better or worst by considering the shadow sector.

It is possible to note, in this sense, that the variance, taking into account all the different components of the composite indicator, shows relevant values for regions with a high range. In particular, when there is a higher variance between the original variables, in this case, we can obtain the relevant radii, which in this case can be interpreted with a different performance on the indicator by using specific groups of variables than other groups of variables. In this sense, the effect of the shadow market could be considered. There is a discrepancy between the index of great economic difficulty and the other variables.

The result seems to be vital because it enables us to identify and measure poverty in Italy. Simultaneously, some regions can be observed where care is very relevant, but the interval's center is very relevant. Simultaneously, however, some variables make it possible to obtain significant variability between the single composite indicators' different results. In this sense, it can be assumed that the interval of the interval-based composite indicator can be determined by the variability of the different initial factors considered in the construction of the composite indicator. 


\section{Conclusions}

The interval-based composite indicators show that the highest values are obtained in Sicily, Campania, Calabria, and Puglia. At the same time, Calabria and Sardegna have a high value for the computed range. These results are consistent with existing literature. Instantaneously, it is possible to observe the different impact of the variables on the final composite indicator, which can be observed on the range of interval-based indicators. Simultaneously, we have considered poverty based on an interval-based composite indicator, which combines and considers several different assumptions. In particular, composite indicators that are based on different assumptions can now be considered. These composite indicators can consider many different assumptions so that they are less sensitive to subjective assessments. In particular, they can consider many different assumptions and consider the different combinations of factors identified in constructing the composite indicator. In the end, the uncertainty of the composite indicator can be "endogenized."

The interval-based composite indicator's center indicates the final value of the composite indicator, which may differ from the value identified on a single scalar composite indicator. The lower bound (the minimum) and the upper bound (the maximum) can also be considered relevant indicators of extreme scenarios that can be usefully compared. Simultaneously, the range has a vital interpretation: we can identify significant differences in the different single indicators, further explored through a multivariate analysis. Final results are more reliable than other composite indicators and can be used for policy purposes.

\section{References}

Abdu, M., \& Delamonica, E. (2018). Multidimensional Child Poverty: From Complex Weighting to Simple Representation. Social Indicators Research, 136(3), 881-905.

Alkire, S., \& Foster, J. (2011). Counting and multidimensional poverty measurement. Journal of public economics, 95(7), 476-487.

Alkire, S., Roche, J. M., Ballon, P., Foster, J., Santos, M. E., \& Seth, S. (2015). Multidimensional poverty measurement and analysis. Oxford University Press, USA.

Anand, S., \& Sen, A. (1997). Concepts or Human Development and Poverty: A Multidimensional Perspective. United Nations Development Programme, Poverty and human development: Human development papers, 1-20.

Asselin, L. M. (2002). Composite indicator of multidimensional poverty. Multidimensional Poverty Theory. Asselin, Louis-Marie. Analysis of multidimensional poverty: Theory and case studies. Vol. 7. Springer Science \& Business Media, 2009. 
Becker, W., Saisana, M., Paruolo, P., \& Vandecasteele, I. (2017). Weights and importance in composite indicators: Closing the gap. Ecological indicators, 80, 12-22.

Billard, L. (2008). Some analyses of interval data. Journal of computing and information technology, 16(4), 225-233.

Billard, L., \& Diday, E. (2003). From the statistics of data to the statistics of knowledge: symbolic data analysis. Journal of the American Statistical Association, 98(462), 470-487.

Bourguignon, F., \& Chakravarty, S. R. (2003). The measurement of multidimensional poverty. The Journal of Economic Inequality, 1(1), 25-49.

Cerioli, A., \& Zani, S. (1990). A fuzzy approach to the measurement of poverty. In income and wealth distribution, inequality and poverty (pp. 272-284). Springer, Berlin, Heidelberg.

Chambers, R. (2006). What is poverty? Who asks? Who answers?. Poverty in Focus UNDP Poverty Centre (IPC)

Costa, M., \& De Angelis, L. (2008). The multidimensional measurement of poverty: a fuzzy set approach. Statistica, 68(3/4), 303-319.

D'Ambrosio, C. (Ed.). (2018). Handbook of Research on Economic and Social Well-being. Edward Elgar Publishing.

De Muro, P., Mazziotta, M., \& Pareto, A. (2011). Composite indices of development and poverty: An application to MDGs. Social indicators research, 104(1), 1-18.

Drago, C. (2017) Interval Based Composite Indicators. FEEM Working Paper No. 42.2017. Available at SSRN: https://ssrn.com/abstract=3038751 or http://dx.doi.org/10.2139/ssrn.3038751

Drago C. (2018) Il monitoraggio della domanda di reddito di cittadinanza in tempo reale facendo uso di Big Data: un'analisi basata su indicatori ad intervallo. V Convegno Nazionale dell'Associazione Italiana per gli Studi sulla Qualità della Vita - Fiesole (FI), 13-15 Dicembre 2018 - Libro dei Contenuti Brevi

Gatto, A., \& Drago, C. (2020). Measuring and modeling energy resilience. Ecological Economics, 172, 106527.

Gioia, F., \& Lauro, C. N. (2005). Basic statistical methods for interval data. Statistica applicata, 17(1), 75104.

Greco, S., Ishizaka, A., Tasiou, M., \& Torrisi, G. (2017). On the methodological framework of composite indices: A review of the issues of weighting, aggregation, and robustness. Social Indicators Research, 1-34.

Grzegorzewski, P. (2018, September). Measures of Dispersion for Interval Data. In International Conference Series on Soft Methods in Probability and Statistics (pp. 91-98). Springer, Cham. 
Hansen, K., \& Kneale, D. (2013). Does how you measure income make a difference to measuring poverty? Evidence from the UK. Social indicators research, 110(3), 1119-1140.

Kakwani, N., \& Silber, J. (Eds.). (2008). Quantitative approaches to multidimensional poverty measurement. Springer.

Kim, S. G. (2016). What Have We Called as "Poverty"? A Multidimensional and Longitudinal Perspective. Social Indicators Research, 129(1), 229-276.

Lemmi, A. A., \& Betti, G. (Eds.). (2006). Fuzzy set approach to multidimensional poverty measurement (Vol. 3). Springer Science \& Business Media.

Lok-Dessallien, R. (1999). Review of poverty concepts and indicators. UNDP Soc Dev Poverty Elimin Div Poverty Reduct Ser from http://www. undp. orgpovertypublicationspovReview pdf, 21.

Maggino, F. (2009). La misurazione dei fenomeni sociali attraverso indicatori statistici. Aspetti metodologici. Working paper, Universita` di Firenze.

Mauro, V., Biggeri, M., \& Maggino, F. (2018). Measuring and monitoring poverty and well-being: A new approach for the synthesis of multidimensionality. Social Indicators Research, 135(1), 75-89.

Mballo, C., \& Diday, E. (2005). Decision trees on interval valued variables. The electronic journal of symbolic data analysis, 3 (1), 8-18

Moore, R. E. (1979). Methods and applications of interval analysis (Vol. 2). Siam.

Mussard, S., \& Noel, P. A. M. (2005). Multidimensional decomposition of poverty: a fuzzy set approach (No. 05-08).

Nardo, M., Saisana, M., Saltelli, A., \& Tarantola, S. (EC/JRC), Hoffman, A., Giovannini, E. (OECD) (2005). Handbook on constructing composite indicators: Methodology and userguide. OECD, statistics working paper

Nyiwul, Linus and Selim, Tarek H., Poverty As Social Deprivation: A Survey (February 2006). Review of Social Economy, Volume 64, 2006 - Issue 2, DOI:10.1080/00346760600721122. Available at SSRN: https://ssrn.com/abstract $=3166455$

Paruolo, P., Saisana, M., \& Saltelli, A. (2013). Ratings and rankings: voodoo or science?. Journal of the Royal Statistical Society: Series A (Statistics in Society), 176(3), 609-634.

Saisana, M., Saltelli, A., \& Tarantola, S. (2005). Uncertainty and sensitivity analysis techniques as tools for the quality assessment of composite indicators. Journal of the Royal Statistical Society: Series A (Statistics in Society), 168(2), 307-323.

Saltelli, A., Ratto, M., Andres, T., Campolongo, F., Cariboni, J., Gatelli, D., ... \& Tarantola, S. (2008). Global sensitivity analysis: the primer. John Wiley \& Sons. 
Saltelli A. (2016) Sensitivity Analysis: an Introduction. Presentation Summer School on Sensitivity Analysis SAMO 2016, Villa Orlandi, Anacapri, July 4-8, 2016

Sen, A. (1982). Poverty and famines: an essay on entitlement and deprivation. Oxford university press.

Sen, A. (1992). Inequality reexamined. Clarendon Press

Sen, A., \& Muellbauer, J. (1988). The standard of living. Cambridge University Press.

Sindzingre, A. (2007). The multidimensionality of poverty: An institutionalist perspective. In The many dimensions of poverty (pp. 52-74). Palgrave Macmillan, London.

Song, P., Liang, J., \& Qian, Y. (2012). A two-grade approach to ranking interval data. Knowledge-Based Systems, 27, 234-244.

Sunaga, T. (1958). Theory of interval algebra and its application to numerical analysis. $R A A G$ memoirs, 2(29-46), 209.

\begin{tabular}{|l|}
\hline Indicators considered and their reference date on the ASVIS database \\
\hline Families living below the threshold of absolute poverty (31/12/2016)-Sotpovas \\
\hline Index of great Economic difficulty (31/12/2016)-Diffeco \\
\hline Percentage of population living in poverty or social exclusion (31/12/2016)-poves \\
\hline index of severe material deprivation (31/12/2016)-depriv \\
\hline individuals in low working-intensity households (31/12/2016)-Basintlav \\
\hline $\begin{array}{l}\text { percentage of people who They live in households with an equivalent disposable income, less than } 60 \% \text { of } \\
\text { median income (31/12/2016)-reddmed }\end{array}$ \\
\hline
\end{tabular}

Table 1. Indicators used 


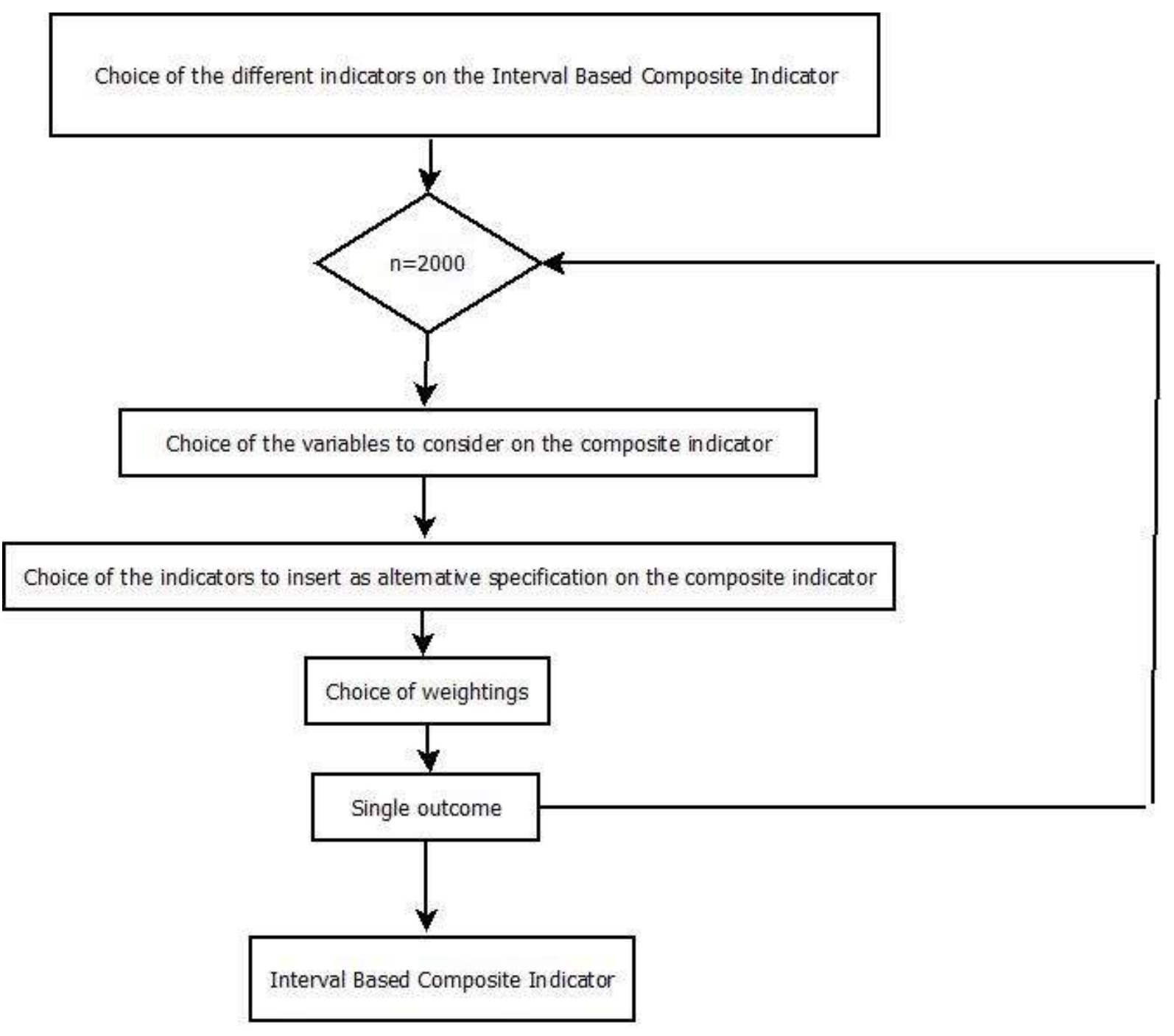

Figure 1. Flow chart of the procedure 


\begin{tabular}{|c|c|c|c|c|}
\hline \multicolumn{2}{|c|}{ sotpovas } & diffeco & poves & depriv \\
\hline Min. & $: 3.580$ & Min. $\quad: 3.90$ & Min. $\quad: 16.10$ & Min. $\quad: 5.00$ \\
\hline lst Qu. & $: 5.755$ & 1st Qu.: & 1st Qu.: 20.10 & 1st Qu.: \\
\hline Median : & $: 10.370$ & Median : 8.80 & Median : 24.40 & Median : 9.40 \\
\hline Mean : & $: 12.434$ & Mean : 11.29 & Mean : 30.28 & Mean : 11.39 \\
\hline 3rd Qu. & $: 16.320$ & 3rd Qu. : 14.80 & 3rd Qu.: 39.00 & 3rd Qu.: :14.55 \\
\hline $\begin{array}{l}\text { Max. } \\
\text { basin: }\end{array}$ & $\begin{array}{l}: 34.940 \\
\text { tav }\end{array}$ & $\begin{array}{c}\text { Max. }: 21.60 \\
\text { reddmed }\end{array}$ & Max. $\quad: 55.60$ & Max. $\quad: 26.10$ \\
\hline Min. & $: 6.10$ & Min. : 8.90 & & \\
\hline lst Qu. & $: 8.35$ & lst Qu.:13.75 & & \\
\hline Median & $: 9.90$ & Median : 16.00 & & \\
\hline Mean & $: 12.74$ & Mean $: 20.84$ & & \\
\hline 3rd Qu. & $: 16.70$ & 3xd Qu.: :27.55 & & \\
\hline Max. & $: 26.70$ & Max. $\quad: 41.80$ & & \\
\hline
\end{tabular}

Table 2. Descriptive Statistics of the indicators considered 


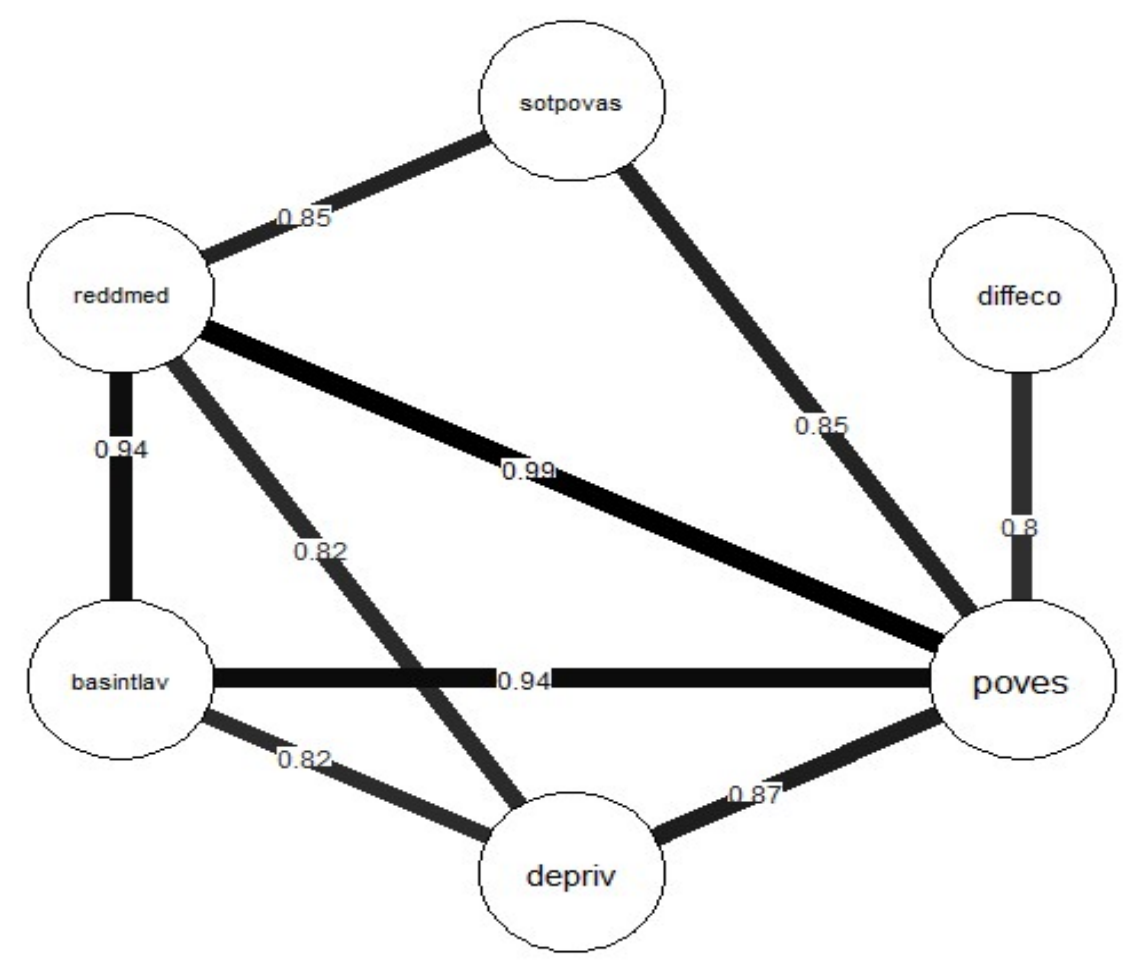

Figure 1. Correlation network (threshold correlation 0.8) 


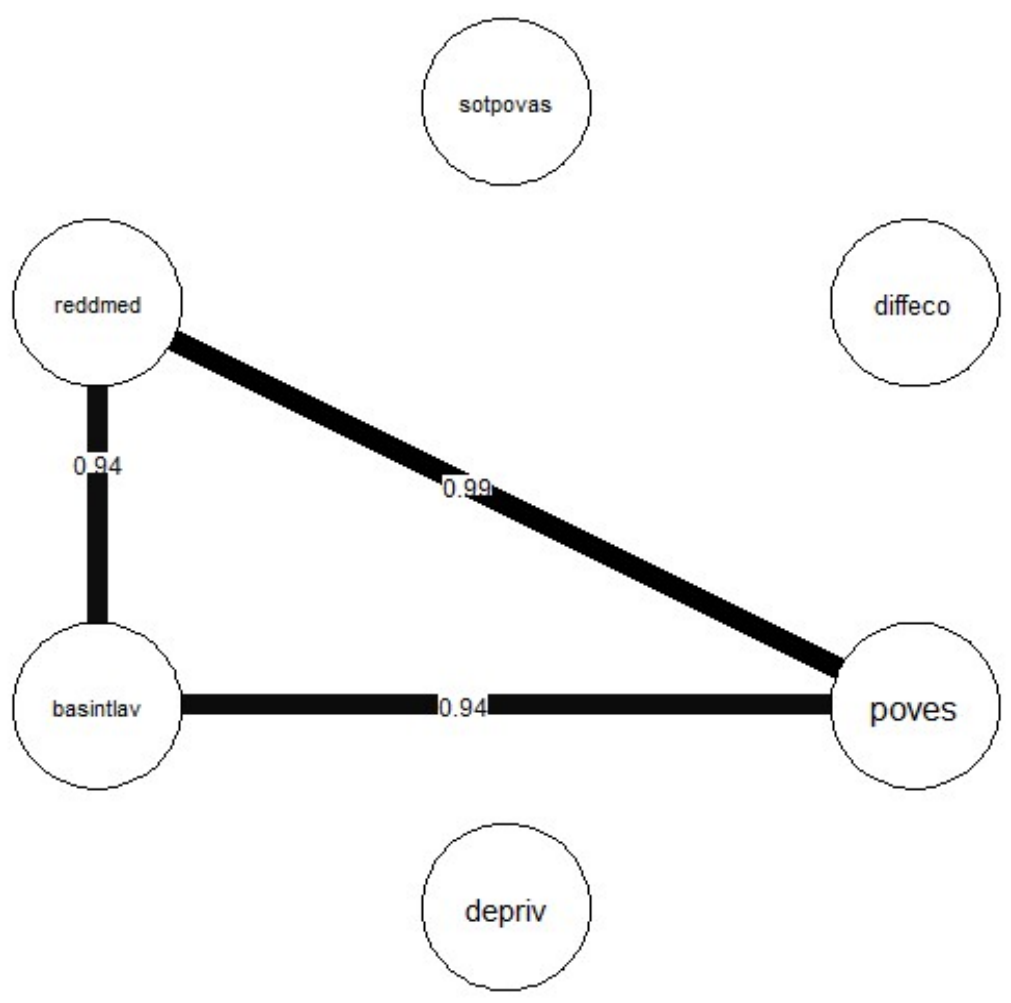

Figure 2. Correlation network (threshold correlation 0.9) 


$\begin{array}{rrrr}\text { Regione } & \text { mini } & \text { center } & \text { maxi } \\ \text { Sicilia } & 1.30488641 & 1.72305356 & 2.14122072 \\ \text { Campania } & 1.27529289 & 1.58504570 & 1.89479852 \\ \text { Calabria } & 0.76714655 & 1.34922259 & 1.93129863 \\ \text { Puglia } & 0.58793760 & 0.86486245 & 1.14178730 \\ \text { Sardegna } & 0.19805132 & 0.72584719 & 1.25364307 \\ \text { Basilicata } & 0.38651178 & 0.71478802 & 1.04306426 \\ \text { Molise } & -0.07454861 & 0.31868843 & 0.71192547 \\ \text { Abruzzo } & -0.21939620 & 0.09571853 & 0.41083326 \\ \text { Lazio } & -0.37419564 & -0.21376999 & -0.05334433 \\ \text { Piemonte } & -0.66504918 & -0.39465823 & -0.12426727 \\ \text { Liguria } & -0.55909841 & -0.45766490 & -0.35623140 \\ \text { Umbria } & -0.59577663 & -0.46264881 & -0.32952100 \\ \text { Marche } & -0.67955232 & -0.54782093 & -0.41608955 \\ \text { Valle d'Aosta } & -0.79928249 & -0.66184344 & -0.52440439 \\ \text { Lombardia } & -0.87370095 & -0.76757834 & -0.66145573 \\ \text { Friuli-Venezia Giulia } & -1.08139524 & -0.82782025 & -0.57424527 \\ \text { Toscana } & -1.09015302 & -0.96892978 & -0.84770655 \\ \text { Emilia-Romagna } & -1.11664152 & -1.01863742 & -0.92063332 \\ \text { Veneto } & -1.14720561 & -1.02278964 & -0.89837367\end{array}$

Table 2. Interval Based Composite indicators: minimum, centre and maximum (ranked for centre) 


$\begin{array}{rrr}\text { Regione } & \text { center } & \text { radius } \\ \text { Calabria } & 1.34922259 & 1.1641521 \\ \text { Sardegna } & 0.72584719 & 1.0555917 \\ \text { Sicilia } & 1.72305356 & 0.8363343 \\ \text { Molise } & 0.31868843 & 0.7864741 \\ \text { Basilicata } & 0.71478802 & 0.6565525 \\ \text { Abruzzo } & 0.09571853 & 0.6302295 \\ \text { Campania } & 1.58504570 & 0.6195056 \\ \text { Puglia } & 0.86486245 & 0.5538497 \\ \text { Piemonte } & -0.39465823 & 0.5407819 \\ \text { Eriuli-Venezia Giulia } & -0.82782025 & 0.5071500 \\ \text { Lazio } & -0.21376999 & 0.3208513 \\ \text { Valle d'Aosta } & -0.66184344 & 0.2748781 \\ \text { Umbria } & -0.46264881 & 0.2662556 \\ \text { Marche } & -0.54782093 & 0.2634628 \\ \text { Veneto } & -1.02278964 & 0.2488319 \\ \text { Toscana } & -0.96892978 & 0.2424465 \\ \text { Lombardia } & -0.76757834 & 0.2122452 \\ \text { Liguria } & -0.45766490 & 0.2028670 \\ \text { Emilia-Romagna } & -1.01863742 & 0.1960082\end{array}$

Table 3. Interval Based Composite indicators: centre and range (ranked for range) 